\title{
Effects of concurrent working memory load on distractor and conflict processing in a name-face Stroop task
}

Citation for published version (APA):

Jongen, E. M. M., \& Jonkman, L. M. (2011). Effects of concurrent working memory load on distractor and conflict processing in a name-face Stroop task. Psychophysiology, 48(1), 31-43.

https://doi.org/10.1111/j.1469-8986.2010.01037.x

Document status and date:

Published: 01/01/2011

DOI:

10.1111/j.1469-8986.2010.01037.x

Document Version:

Publisher's PDF, also known as Version of record

\section{Document license:}

Taverne

Please check the document version of this publication:

- A submitted manuscript is the version of the article upon submission and before peer-review. There can be important differences between the submitted version and the official published version of record.

People interested in the research are advised to contact the author for the final version of the publication, or visit the DOI to the publisher's website.

- The final author version and the galley proof are versions of the publication after peer review.

- The final published version features the final layout of the paper including the volume, issue and page numbers.

Link to publication

\footnotetext{
General rights rights.

- You may freely distribute the URL identifying the publication in the public portal. please follow below link for the End User Agreement:

www.umlib.nl/taverne-license

Take down policy

If you believe that this document breaches copyright please contact us at:

repository@maastrichtuniversity.nl

providing details and we will investigate your claim.
}

Copyright and moral rights for the publications made accessible in the public portal are retained by the authors and/or other copyright owners and it is a condition of accessing publications that users recognise and abide by the legal requirements associated with these

- Users may download and print one copy of any publication from the public portal for the purpose of private study or research.

- You may not further distribute the material or use it for any profit-making activity or commercial gain

If the publication is distributed under the terms of Article $25 \mathrm{fa}$ of the Dutch Copyright Act, indicated by the "Taverne" license above, 


\title{
Effects of concurrent working memory load on distractor and conflict processing in a name-face Stroop task
}

\section{ELLEN M. M. JONGEN AND LISA M. JONKMAN}

Department of Cognitive Neuroscience, Faculty of Psychology and Neuroscience, Maastricht University, Maastricht, The Netherlands

\begin{abstract}
To examine the time course of effects of working memory (WM) load on interference control, ERPs were measured in a combined WM and Stroop task. A WM load of 0, 2, or 4 letters was imposed, and during the maintenance-interval Stroop trials were presented that required participants to classify names of famous people while ignoring faces that were either congruent or incongruent with the names.

Behavioral interference was not modulated by WM load, but WM load led to an overall reduction of Stroop stimulus encoding as reflected by reduced N170 and N250 amplitudes independent of congruency. Incongruent distractor faces induced interference as shown by a delayed and reduced positivity between 480-600 ms (N450) and an enhanced positivity between 760-1000 ms (P600), indicating longer stimulus evaluation, conflict detection, and conflict resolution, respectively. WM load led to an increase of the P600 at frontal and parietal sites, possibly reflecting PFCdriven top-down control of posterior sites, necessary for conflict resolution.
\end{abstract}

Descriptors: Stroop interference, WM load, ERPs

Attentional mechanisms are important to prioritize and select relevant information in the face of distracting information. Interference from distracting information occurs when inhibition of it fails. Recent studies have shown that working memory (WM) capacity is an important predictor of performance in tasks that place high demands on selective attention, such as flanker or Stroop paradigms (Heitz \& Engle, 2007; Kane \& Engle, 2003; Redick \& Engle, 2006). These findings support WM models that have defined WM capacity as an executive construct (Baddeley, 1993; Conway, Cowan, \& Bunting, 2001; Kane, Conway, Bleckley, \& Engle, 2001; Kane \& Engle, 2003), responsible for active maintenance of goal-relevant information in face of concurrent processing, interference, and conflict.

Further evidence for the interrelatedness of WM and attention comes from different disciplines, such as studies showing overlap in neural substrates (e.g., Corbetta \& Shulman, 2002; LaBar, Gitelman, Parrish, \& Mesulam, 1999; Mayer, Bittner, Nikolic, Bledowski, Goebel, \& Linden, 2007; McNab, Leroux, Strand, Thorell, Bergman, \& Klingberg, 2008; Pessoa \& Ungerleider, 2004; Pollmann \& von Cramon, 2000), and studies showing behavioral and neurobiological evidence for enhanced

We would like to thank Judith Peters and Valerie Goffaux for comments on an earlier version of this manuscript. Furthermore, we thank Ron Hellenbrand and Erik Bongaerts for technical assistance and Lies Vos for her help in data collection.

Address correspondence to: Ellen M. M. Jongen, Department of Work and Social Psychology, Faculty of Psychology and Neuroscience, Maastricht University, P.O. Box 616, 6200 MD Maastricht, The Netherlands. E-mail: E.Jongen@maastrichtuniversity.nl distractor processing when WM resources were reduced by experimental manipulations of WM load (for a review, see Lavie, 2005). For example, in the fMRI study by De Fockert, Rees, Frith, and Lavie (2001), a face-name Stroop ask was conducted in the maintenance interval of a concurrent WM task while WM load was either low or high. In the Stroop task, written names of famous politicians and pop stars were superimposed on pictures of faces from the same set of people. Participants were asked to categorize names as politicians or pop stars while ignoring distractor faces that were either identity-congruent (e.g., the name and face of "Bill Clinton," the politician), or category-incongruent (e.g., the name "Bill Clinton" as a politician superimposed on the face of "Elvis Presley," the singer). Distractor interference, representing the delay in reaction time to classify names superimposed on incongruent faces relative to congruent faces, was larger during high $(73 \mathrm{~ms})$ than low $(32 \mathrm{~ms})$ concurrent WM load. Furthermore, higher WM load was related to enhanced activity in frontal WM-related brain areas and in faceprocessing areas. The latter was suggested to indicate enhanced distractor processing. The authors concluded that high WM load had consumed the resources necessary for interference control in the Stroop task, leading to enhanced distractor processing in face-processing areas and larger interference. This conclusion is in line with Lavie's WM load theory of selective attention (1995; Lavie, Hirst, De Fockert, \& Viding, 2004).

According to Load theory, an active top-down mechanism of attentional control mediated by prefrontal cortical areas depends on WM and plays an important role in the maintenance of goaldirected behavior in the presence of interference (Lavie et al., 
2004). When WM is loaded, distractor interference in a Stroop task is suggested to increase because resources necessary for goal maintenance are consumed by concurrent WM processes. Evidence for this theory has been shown, mainly by Lavie and coworkers, in a number of studies (for a review, see Lavie, 2005). In addition to evidence in line with Load theory (De Fockert et al., 2001; Lavie \& De Fockert, 2005; Pecchinenda \& Heil, 2007), there are also behavioral studies that did not replicate WM load effects on interference control when using other paradigms (Kim, Kim, \& Chun, 2005; Park, Chun, \& Kim, 2007; Woodman, Vogel, \& Luck, 2001). Furthermore, there is still lack of clarity about the brain mechanisms involved in such interactions of WM and interference control. Whereas De Fockert et al. (2001) showed higher frontal and face-processing activation during Stroop processing under high as compared to low WM load, these effects were based on a condition comparison of faceabsent and face-present Stroop stimuli. Effects of WM-load on brain activation related to distractor interference processing can, however, only be investigated directly by comparing name-face congruent and name-face incongruent stimuli. To the best of our knowledge, there are no studies that directly investigated brain mechanisms involved in WM-load effects on distractor interference processing by comparing brain activity in congruent and incongruent Stroop conditions, in which target and distractors are presented simultaneously. Finally, due to poor temporal resolution, fMRI studies have not provided information about when in time processes of Stroop interference are affected by processes of WM. An increase in WM load and resulting reduction in cognitive control may affect early processes of stimulus encoding and recognition, or later processes of stimulus identification and response planning.

The aim of the present study is to gain more insight in the brain mechanisms involved in the effects of WM on interference control that have been reported in the behavioral literature as reviewed above. More specifically, the temporal locus of the effects of WM on interference control will be examined using event-related potential (ERP) measures. To this aim, a manual name-face Stroop task similar to that used in other studies that have reported reliable distractor interference effects will be used (De Fockert et al., 2001; Egner \& Hirsch, 2005; Pecchinenda \& Heil, 2007). The advantage of face distractors is that they are hard to ignore compared to other types of distractors (e.g., Lavie et al., 2003). Furthermore, specific face-processing components in the ERP literature have been related to the different stages of face processing, enabling the investigation of load effects on different stages of face-distractor processing. To investigate effects of WM load, Stroop stimuli will be presented in the maintenance interval of a concurrent WM task, and WM load will be manipulated parametrically asking participants to memorize no letters ( 0 -load condition), 2 letters (2-load condition), or 4 letters (4-load condition). Some hypotheses can be derived from the ERP face-processing literature and the ERP Stroop literature and will be outlined below.

The time course of name-face interference. In the name-face Stroop task, interference only occurs when the identity of distractor face stimuli interferes with the superimposed target name stimuli that participants are asked to classify. Therefore, distractor interference in the ERP signal is hypothesized to occur when or after face identity is processed. For face recognition to take place, individual face features and their spatial relation are analyzed first during an encoding stage before faces are recog- nized, with recognition occurring in separate subsequent stages; whereas visually-derived semantic information such as gender becomes available regardless of face-familiarity, semantic information such as occupation is retrieved in the next processing stage (Bruce \& Young, 1986). In the ERP, the earliest component associated with face processing is the N170, a negative component with a latency of about $170 \mathrm{~ms}$ that is elicited at lateral posterior temporal sites (e.g., Allison, Ginter, McCarthy, Nobre, Puce, et al., 1994; Bentin, Allison, Puce, Perez, \& McCarthy, 1996; Bötzel, Schulze, \& Stodieck, 1995). As it is elicited by the perception of a face regardless of face-familiarity or task relevance (Bentin \& Deouell, 2000; Eimer, 2000a, b; Rossion, Campanella, Gomez, Delinte, Debatisse, et al., 1999; Tanaka, Curran, Porterfield, \& Collins, 2006), it is assumed to reflect processes of structural encoding that occur before face identification (Bentin et al., 1996; Itier \& Taylor, 2004; Latinus \& Taylor, 2006). The earliest face processing ERP component related to face recognition occurs at temporal-occipital sites around $250 \mathrm{~ms}$ after stimulus onset (Pfütze, Sommer, \& Schweinberger, 2002; Schweinberger, Pfütze, \& Sommer, 1995). This N250 component is associated with face recognition because of its sensitivity to manipulations of face familiarity (Begleiter, Porjesz, \& Wang, 1995; Herzmann, Schweinberger, Sommer, \& Jentzsch, 2004; Itier \& Taylor, 2004; Paller, Ranganath, Gonsalves, LaBar, Parrish, et al., 2003; Schweinberger et al., 1995; Tanaka et al., 2006). ERP differences occurring after $400 \mathrm{~ms}$ have been associated with the final stage of face recognition and identification that requires the retrieval of face-associated information from semantic memory, such as in our task (Bentin \& Deouell, 2000; Eimer, 2000a, b; Paller, Gonsalves, Grabowecky, Bozic, \& Yamada, 2000). Recognition-related activity at this stage generally has a broader scalp distribution (Boehm \& Sommer, 2005; Paller, Bozic, Ranganath, Grabowecky, \& Yamada, 1999; Paller et al., 2000, 2003) that is suggested to result from the rapid interactions between a broad network of frontal and temporal cortical areas linked to each other directly and via hippocampal networks (Paller et al., 2003).

Based on the fact that interference in the name-face Stroop task used in the current study can only occur after a face has been identified as a pop star or politician, distractor interference effects are expected in the time range of the broadly distributed ERP components that start about 400 to $600 \mathrm{~ms}$ after face onset and not on the early occipital N170 and N250 components. This time range for name-face interference is also in line with the color-word Stroop ERP literature that consistently describes two interference components: the "N450" and the "P600" (e.g., Lansbergen, van Hell, \& Kenemans, 2007; Liotti, Woldorff, Perez III, \& Mayberg, 2000; Markela-Lerenc, Ille, Kaiser, Fiedler, Mundt, \& Weisbrod, 2004; Qiu, Luo, Wang, Zhang, \& Zhang, 2006; West, 2003; West, Bowry, \& McConville, 2004). The N450 represents a broadly distributed reduced positive component in the incongruent condition relative to the congruent condition between $350-500 \mathrm{~ms}$ and has been associated with the process of conflict monitoring. The P600 represents a broadly distributed enhanced positive component in the incongruent condition relative to the congruent condition starting around $600 \mathrm{~ms}$ and has been attributed to conflict resolution.

The time course of effects of WM on name-face interference. According to load theory, interference from incongruent distractor faces will increase when concurrent WM load increases 
due to depletion of resources that are necessary for goal maintenance in the Stroop task (Lavie et al., 2004). With respect to the time course of these effects, interference from incongruent distractor faces is expected to occur on the N450 and P600 Stroop interference ERP components, and increases are expected at the same latency.

Since the N170 and N250 components represent early face encoding stages that are thought to originate from secondary visual areas (Schweinberger, Huddy, \& Burton, 2004; Schweinberger, Pickering, Jentzsch, Burton, \& Kaufman, 2002a) and precede the stage of face identification, no interference effects or interaction of $\mathrm{WM}$ and interference are expected around this time of stimulus processing. Still, an increase in WM load may have a main effect on early face encoding stages (N170 and $\mathrm{N} 250$ ) in the Stroop task, independent of whether faces are congruent or incongruent. As mentioned above, using a similar paradigm, De Fockert et al. (2001) reported enhanced fMRI activation in face-processing areas when concurrent WM load was imposed. This was, however, based on a comparison of face absent (word only) and face present (word superimposed on face) stimuli. Whereas ERP studies have also provided evidence for topdown influences of WM on the latency or amplitude of the N170 and N250 components (e.g., Gazzaley, Cooney, McEvoy, Knight, \& D'Esposito, 2005; Morgan, Klein, Boehm, Shapiro, \& Linden, 2008; Sreenivasan \& Jha, 2007), these studies did not investigate effects of parametric WM-load manipulations and/or did not present target and distractor stimuli simultaneously, creating semantic conflict, such as in the name-face Stroop task. Based on Load theory and results by De Fockert et al. (2001), it can be predicted that, with an increase of WM load, there will be fewer resources available for target maintenance, leaving more room for distractor (face) processing. This might be reflected by enhanced amplitudes of the face-sensitive N170 and N250 components and reductions in N170 latency in lateral-occipital cortex in response to distracting face stimuli, independent of face-name congruency.

\section{Method \\ Participants}

Thirty volunteers (age 18.4-33.3, mean age 22.2, 23 female), all students from Maastricht University, participated in the study. All gave informed consent and received course-credits or were paid $(€ 22.50)$ for participation. The experimental methods had ethical approval from the institutional ethics committee. An estimation of full-scale IQ was derived from the individual scores on two subtests (vocabulary and block design) of the Dutch version of the Wechsler Adult Intelligence Scale (WAIS-III); mean IQ-score was 123.1 (range 103-139, SD 10.2). As a measure of WM capacity, participants performed the digit span test (forward and backward), which is part of the WAIS-III. The standardized mean digit span score was 12.7 (range 6-18, SD 3.1).

\section{Stimuli}

Memory stimuli. The memory set consisted of a row of 2 (2load condition) or 4 (4-load condition) consonant letters (excluding Y and Q), or 4 star stimuli (*; 0-load condition). Letter size was $0.37 \mathrm{~cm}$ horizontally $\times 0.48 \mathrm{~cm}$ vertically, and star size was $0.2 \mathrm{~cm}$ horizontally $\times 0.3 \mathrm{~cm}$ vertically. ${ }^{1}$ The size of the

\footnotetext{
${ }^{1}$ At a viewing distance of $57 \mathrm{~cm}, 1 \mathrm{~cm}$ on the display subtends $1^{\circ}$ of visual angle.
}

memory set was $3.8 \mathrm{~cm}$ horizontally $\times 0.3 \mathrm{~cm}$ vertically in the 0 -load condition, $1.5 \mathrm{~cm}$ horizontally $\times 0.48 \mathrm{~cm}$ vertically in the 2-load condition, and $3.8 \mathrm{~cm}$ horizontally $\times 0.48 \mathrm{~cm}$ vertically in the 4-load condition. Memory probe stimuli consisted of one letter in the 2-load and 4-load condition, or an arrow to the left $(<<)$ or to the right $(>>)$ in the 0 -load condition. Arrow size was $1 \mathrm{~cm}$ horizontally $\times 0.4 \mathrm{~cm}$ vertically.

Stroop stimuli. Stroop stimuli consisted of photographs and names of famous pop stars and well-known politicians. The photographs were derived from the World Wide Web. The selection of pop stars and politicians to be included in the nameface Stroop task was based on a screening. University students ( $n=66$; Dutch native speakers) were presented with photographs of faces of 30 politicians and 38 pop stars and asked to write down the correct name below each photo. Based on recognition rates, 4 famous pop stars (between brackets: percentage of students that correctly recognized the face): Michael Jackson (95\%), Elvis Presley (92\%), Justin Timberlake (97\%), and Robbie Williams (97\%), and 4 well-known politicians: George Bush (98\%), Bill Clinton (94\%), Jan Peter Balkenende (82\%; Dutch prime minister), Geert Wilders (82\%; Dutch minister) were selected. Participants from the screening familiar with at least 7 of the 8 selected faces were invited to participate in the main study.

All photographs were software-edited using Adobe Photoshop. Faces were first converted to grayscale, the background was set to gray (RGB; 131, 131, 131), and image height was adjusted to 250 pixels. In Matlab (version R2007a), average face luminance was adjusted to the average background luminance. In the task, the size of the faces ranged from $4.6-5.4 \mathrm{~cm}$ horizontally $\times 7.3 \mathrm{~cm}$ vertically. Name stimuli consisted of first names and surnames, presented next to each other and below the eyes of the face, in dark gray color (RGB; 64, 64, 64), with size ranging from $3.0-5.3 \mathrm{~cm}$ horizontally $\times 0.5 \mathrm{~cm}$ vertically.

\section{Task Description}

The task was a combination of a Sternberg WM (item recognition) task and a name-face Stroop paradigm (see Figure 1). On every trial (see Figure 1A), after a fixation cross $(300 \mathrm{~ms})$, a memory set was presented $(1500 \mathrm{~ms})$, followed by an inter-stimulus interval (ISI; $850 \mathrm{~ms}$ ) during which a fixation cross was presented. In the maintenance delay, a sequence of either two Stroop trials (in 33\% of all cases) or three Stroop trials (in 67\% of all cases) was presented. Each Stroop stimulus was presented for $1000 \mathrm{~ms}$, and followed by an ISI $(1500 \mathrm{~ms})$ during which a fixation cross was presented. Finally, the memory probe was presented $(1500 \mathrm{~ms})$, followed by a fixation cross $(200 \mathrm{~ms})$.

In the Sternberg WM task (see Figure 1B), the memory set consisted of a row of 2 (2-load condition) or 4 (4-load condition) randomly selected and randomly ordered consonant letters, or 4 star stimuli (*; 0-load condition). Participants were instructed only to perceive the star stimuli, and to memorize the letter stimuli during the maintenance interval. After the maintenance interval, the memory probe was presented, consisting of one letter that either had been part of the memory set (positive probe) or had not been part of the memory set (negative probe) in the 2load and 4-load condition, or an arrow to the left $(<<)$ or to the right $(>>)$ in the 0-load condition. Participants were instructed to discriminate positive versus negative probes and arrows left versus arrows right by pressing the left-hand or the right-hand response button using their index-fingers. Left and right button 


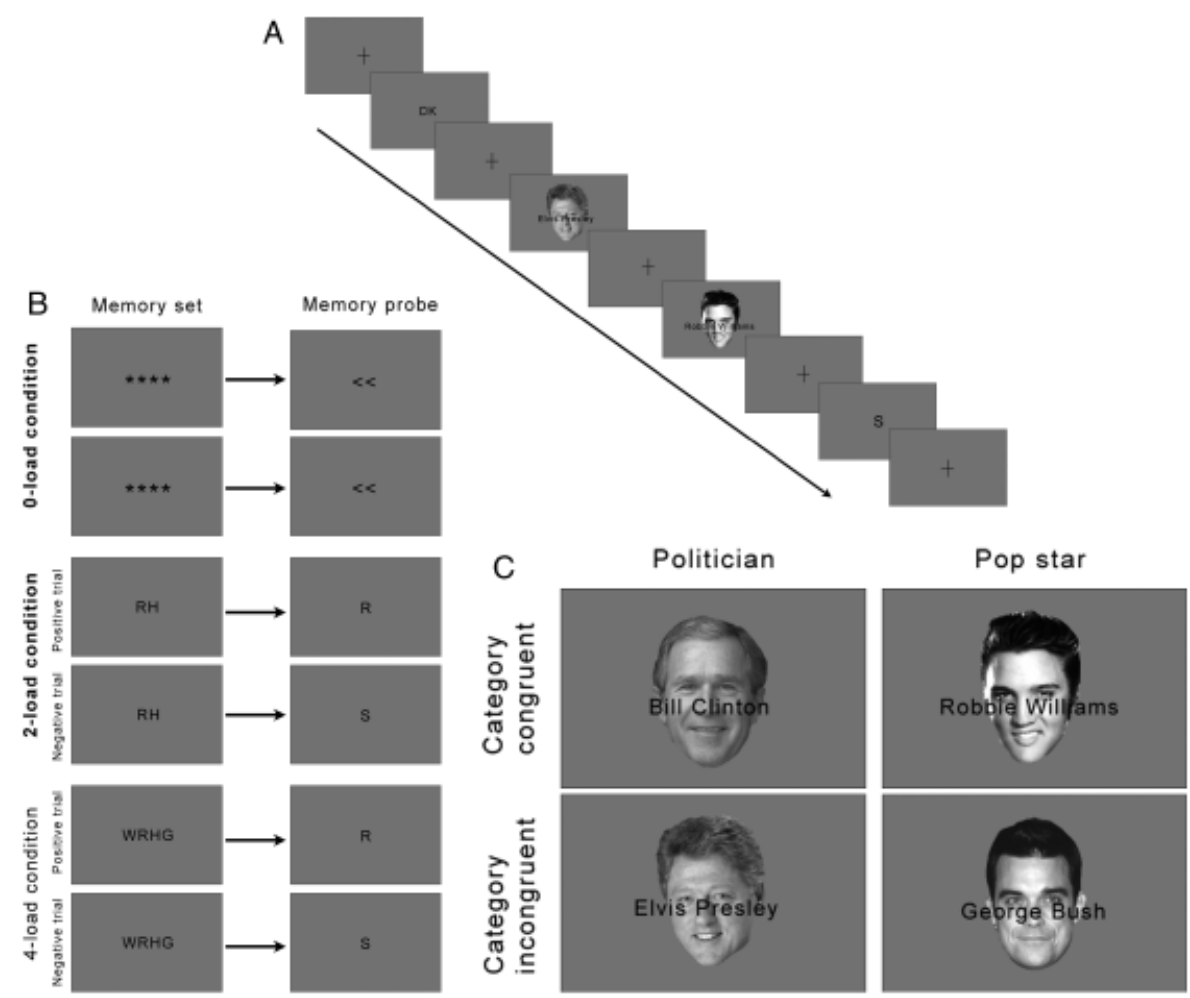

Figure 1. (A) Schematic illustration of a trial. In this example of a 2-load memory trial, 2 letters are followed by a category-incongruent Stroop stimulus, a category-congruent Stroop stimulus, and a negative memory probe stimulus. Stimuli are not to scale. Subjects were instructed to memorize the letter stimuli, and subsequently classify written name stimuli (while ignoring face stimuli) as either a pop star or a politician. Finally, participants were to decide if the letter stimulus had been part or had not been part of the to-be-memorized sequence of letters. In both the memory task and the Stroop task, participants were asked to respond as fast and accurately as possible by pressing the correct response button (two-choice button response). (B) Schematic representation of memory trials in the 0-load, 2-load, and 4-load condition. (C) Schematic representation of the category-congruent and categoryincongruent conditions for the two categories that were used in the task: pop stars and politicians. In the category-congruent condition, written name stimuli and face stimuli were from the same category; in the category-incongruent condition, written name stimuli and face stimuli were from opposite categories.

allocation for positive and negative probes (but not for left and right arrows) was balanced between subjects.

In the name-face Stroop paradigm (see Figure 1C), written names of famous pop stars and well-known politicians were superimposed on faces from the same set of pop stars or politicians. The faces were equally likely to be category-congruent with the target name (e.g., a pop star's face and another pop star's name), or category-incongruent with the target name (a pop star's face and a politician's name or vice versa). No face stimulus was combined with its own name. The task was thus slightly different from the task used by De Fockert et al. (2001), in which the congruent condition consisted of faces paired with their own name (i.e., identity-congruency). The advantage of categorycongruency (Egner \& Hirsch, 2005; Pecchinenda \& Heil, 2007) is the larger number of unique congruent stimuli relative to identity-congruency which compensates the larger number of trials and repetition of stimuli in an EEG study, and more importantly results in a comparable number of unique stimuli in the congruent and incongruent condition, thereby controlling factors such as stimulus novelty between conditions that might otherwise confound the results. Participants were instructed to classify the names as either pop star or politician while ignoring distractor faces by pressing the left-hand or the right-hand response button using their index fingers. Left and right button allocation for the two response categories was balanced between subjects.
Corrective feedback (short text message) was given on misses, false alarms, and on responses that were too fast $(<120 \mathrm{~ms})$, or too slow ( $>1750 \mathrm{~ms}$ Stroop stimuli; $>1500 \mathrm{~ms}$ memory probes).

The experimental session comprised 432 Stroop trials and 162 WM trials, presented in 9 separate blocks (3 blocks for each memory load) of 48 Stroop trials and 18 memory trials. An additional warming-up trial was presented at the start of each block and not included in the analyses. In each block, positive and negative probes were equiprobable and presented randomly, and category-congruent and category-incongruent stimuli were equiprobable and presented randomly. The blocks were presented in pseudo-random order following the restriction that each of the three load conditions was presented once before any of the load conditions were repeated (e.g., 024042 420). Six different orders were used across subjects. Between blocks, participants could take a short break.

\section{Procedure}

The experiment was conducted in a dimly lit, sound-attenuated room, on a Samsung SyncMaster 940BF monitor that was placed at a viewing distance of $57 \mathrm{~cm}$. ERTSVIPL V3.37b (Beringer, 1987) controlled the tasks. After the preparations for the electroencephalographic (EEG) recordings, participants performed a blink calibration task (Jongen, Smulders, \& van Breukelen, 2006; Jongen, Smulders, \& van der Heiden, 2007), in which spontaneous blinks were promoted by demanding con- 
stant fixation to detect slow color changes of a fixation cross. The blink correction factor was derived from this task and used for offline correction of trials with eyeblinks in the main task (see below). The main task session was then presented. ${ }^{2}$ The experimental session was preceded by an extensive practice session ${ }^{3}$ that served to ensure face-familiarity and name-face association, to practice the Stroop task, the working memory task, and the combined task. After removal of the EEG cap, three subtests of the WAIS-III were performed.

\section{EEG Recording and Analyses}

EEG activity was recorded continuously, via NeuroScan 4.3 (Compumedics, Hamburg, Germany), from 62 channels, using tin electrodes mounted on an elastic cap (Easycap) and positioned according to the 10-20 System. The left mastoid (A1) was used as the reference for all electrodes, and AFz functioned as the ground. Tin electrodes were also used to bipolarly record vertical and horizontal electrooculograms (EOGs). Electrode impedance was kept below $5 \mathrm{k} \omega$ during recording, amplifier bandpass was $0.05-100 \mathrm{~Hz}$, and the digitization rate was $500 \mathrm{~Hz}$.

ERP analysis was done in Neuroscan 4.3.1. EEG data were re-referenced off-line to the average of the right and left mastoids. Eyeblink activity was corrected with a regression procedure (Semlitsch, Anderer, Schuster, \& Presslich, 1986) using the blink correction coefficients derived from the blink calibration task. Data were filtered with a low pass filter of $30 \mathrm{~Hz}$ ( $48 \mathrm{~dB} /$ oct.) and then separated into epochs of $1200 \mathrm{~ms}$, starting $200 \mathrm{~ms}$ before Stroop stimulus onset. Incorrect Stroop trials, and Stroop trials with a voltage exceeding $\pm 100 \mu \mathrm{V}$ were excluded from the analyses. Furthermore, to reliably examine the effect of WM load on processes of Stroop interference, only Stroop trials within the WM delay of correct WM trials were included. Averages were computed relative to the $200 \mathrm{~ms}$ baseline for each subject, for each of the twelve conditions (WM Load conditions $(0,2,4) \times$ Congruency (2: congruent, incongruent) $\times$ Stimulus type $(2$ : politicians, pop stars)). Grand averages were then computed for each of the six (WM Load $\times$ Congruency) conditions, disregarding Stimulus type.

After exclusion of trials with a voltage exceeding $\pm 100 \mu \mathrm{V}$ and error trials, a trial-average (range, S.D.) of $68.6(61-72,3.1)$ in the Congruent 0-load condition; $66.2(58-72,4.2)$ in the Incongruent 0 -load condition; $64.5(52-72,4.9)$ in the Congruent 2-load condition; $62.6(52-72,4.7)$ in the Incongruent 2-load condition; $64.2(48-72,5.5)$ in the Congruent 4-load condition; $61.9(46-70,6.1)$ in the Incongruent 4-load condition remained for analyses.

Distractor (face) processing at P07/PO8: N170 and $N 250$. Based on the literature discussed in the introduction and inspection of grand averages (see Figure 2, Figure 3), the mean amplitude of the N170 (180-220 ms) and N250 (280-340 $\mathrm{ms}$ ) were computed at electrodes PO7/PO8. Furthermore, for N170 peak latency, the amplitude minimum was determined in a 160-240 ms window after filtering the ERPs using an $8 \mathrm{~Hz}(12$ $\mathrm{dB} /$ oct.) low pass filter.

\footnotetext{
${ }^{2}$ Participants also performed another combined working memory and interference control task (task order was balanced across participants); these data will be discussed elsewhere.

${ }^{3}$ More details about the practice session can be obtained from the first author.
}

Interference processing: broadly distributed positivity reduction (N450) and positivity enhancement (P600). Two interference effects were expected: a positivity reduction (N450) and a positivity enhancement (P600) for the incongruent condition relative to the congruent condition. Inspection of grand averages (see Figure 4) indeed revealed these two interference effects.

The N450 was most pronounced between $480-600 \mathrm{~ms}$ and broadly distributed over midline and lateral fronto-central, centroparietal, parietal, and parieto-occipital sites (see voltage maps in Figure 4). Thus, for statistical analysis ERP mean amplitudes in the specified window $(480-600 \mathrm{~ms})$ in these scalp regions were selected using midline sites and two adjacent lateral sites $(\mathrm{FCz} / 3 /$ 4; $\mathrm{CPz} / 3 / 4 ; \mathrm{Pz} / 3 / 4 ; \mathrm{POz} / 3 / 4)$. As shown in Figure 3, the positivity showed a latency delay for incongruent trials in comparison to congruent trials. A similar P3 peak latency delay for incongruent relative to congruent stimuli has been shown in the colorword Stroop task (Lansbergen \& Kenemans, 2008). It was interpreted as indicating longer stimulus identification and evaluation time in the incongruent relative to the congruent condition (Kutas, McCarthy, \& Donchin, 1977). Positivity latency was therefore estimated at the same selection of channels as the N450 in the 400-1000 ms time window in single trials, after $3.4 \mathrm{~Hz}$ low pass filtering (Lansbergen \& Kenemans, 2008; Smulders, Kenemans, \& Kok, 1994).

The P600 was most pronounced between $760-1000 \mathrm{~ms}$, and broadly distributed over midline and lateral frontal, fronto-central, parietal, and occipital sites (see voltage maps in Figure 4). Thus, for statistical analysis ERP mean amplitudes in the specified window (760-1000 ms) in these scalp regions were selected using midline sites and two adjacent lateral sites $(\mathrm{Fz} / 3 / 4, \mathrm{FCz} / 3 /$ $4, \mathrm{Pz} / 3 / 4, \mathrm{Oz} / 1 / 2)$.

\section{Behavioral Statistical Analyses}

Working memory. After exclusion of error WM trials, a WM trial-average (range, S.D.) of $53.7(53.0-54.0,0.45)$ in the 0-load condition, $50.3(43.0-53.0,2.3)$ in the 2-load condition, and 50.0 $(37.0-53.0,3.2)$ in the 4-load condition remained for analyses. Reaction time data and the square roots of percentages of misses, false alarms, and hits were analyzed in an analysis of variance (ANOVA) with Load (3: 0-load, 2-load, 4-load) as within-subjects factor.

Stroop. Reaction time data and the square roots of percentages of misses, false alarms, and hits were analyzed using an overall Load (3: 0-load, 2-load, 4-load) $\times$ Congruency (2: congruent, incongruent) ANOVA.

\section{ERP Statistical Analysis}

Statistical ERP analysis was carried out by entering mean voltage values in the specified time windows (for every described component) and peak latency values (for the N170 and positivity delay (400-1000 ms)) into an ANOVA. In all analyses, withinsubjects factors Load (3: 0-load, 2-load, 4-load) and Congruency (2: congruent, incongruent) were included. Additional withinsubjects factors in the analyses of the positivity reduction (N450) and enhancement (P600) were Anterior-Posterior (N450: FC, CP, P, PO; P600: F, FC, P, O) and Laterality (3: left, midline, right). An additional within-subjects factor in the analyses of the N170 and the N250 was Hemisphere (2: left (PO7), right (PO8)).

For all analyses, $p$-value was set at .05 , corrected for deviations from sphericity (Greenhouse-Geisser epsilon correction). 

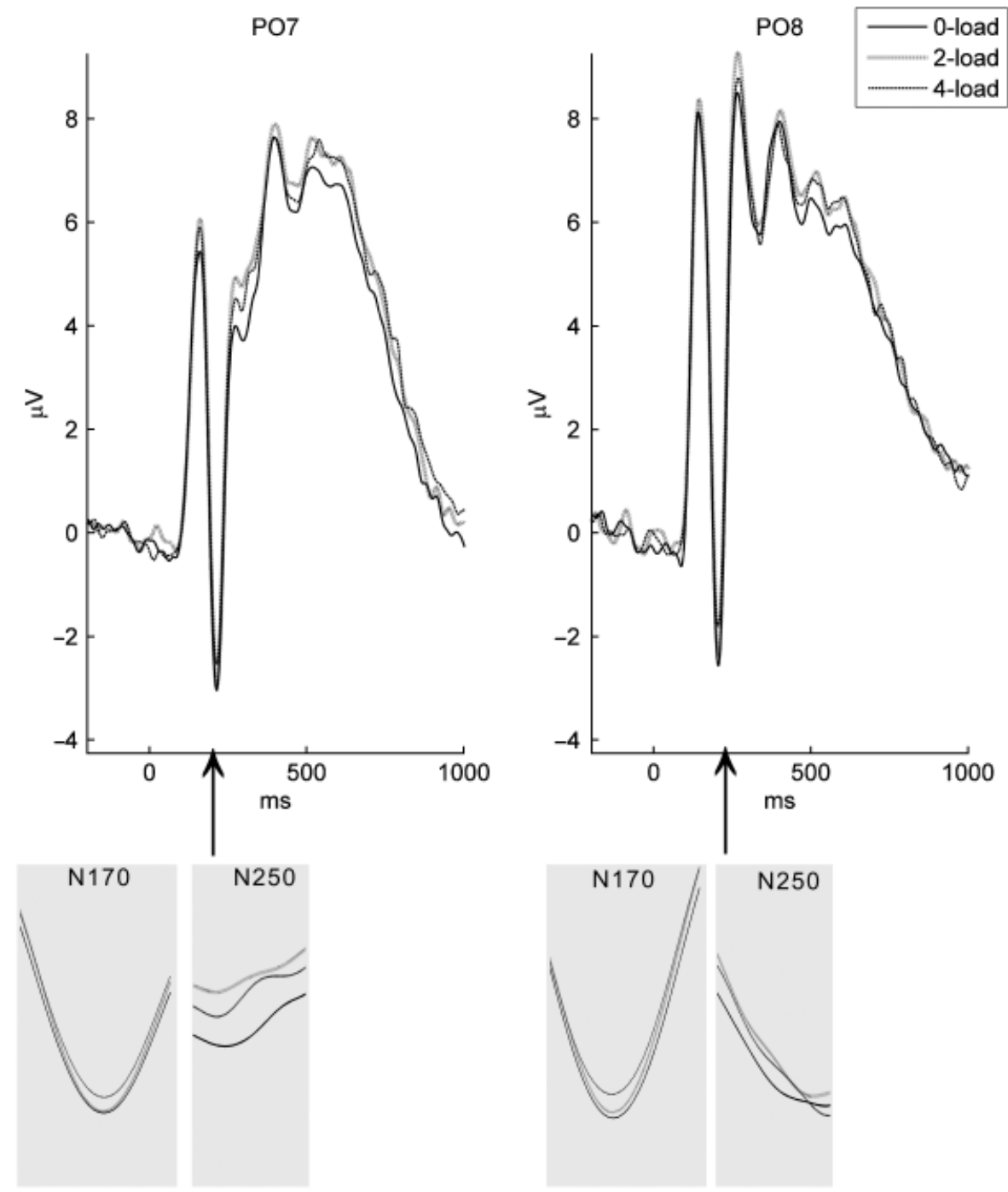

Figure 2. Grand-averaged ERPs elicited by name-face Stroop stimuli at PO7 and PO8, for the 0-load (black line), 2-load (gray line), and 4-load (dotted line) condition (pooled for congruency). The N170 (180-220 ms) and N250 (280-340 ms) are presented enlarged.

The corrected $F$ - and probability values, and the uncorrected degrees of freedom are reported.

\section{Results}

\section{Working Memory Task Performance}

Average reaction times and the average percentage of false alarms, misses, and hits to memory probe stimuli as a function of WM load are summarized in Table 1.

Accuracy. Since the average percentage of misses was smaller than $1 \%(.54)$, these data were not further analyzed. False alarms increased with load (Load: $F(2,58)=134.5, p<.0005)$. Planned comparisons showed a significant increase in false alarms from 0 load to 2-load $(p<.0005)$ and from 0 -load to 4-load $(p<.0005)$, but not from 2-load to 4-load $(p=1.0)$. Hits decreased when load increased (Load: $F(2,58)=33.1, p<.0005)$, and planned comparisons showed a significant decrease from 0 -load to 2-load $(p<.0005)$, and from 0 -load to 4-load $(p<.0005)$, but not from 2-load to 4-load $(p=1.0)$.

Reaction time. As expected, reaction times increased with load (Load: $F(2,58)=195.0, p<.0005)$. Planned comparisons showed a significant increase in reaction time from 0 -load to 2-load $(p<.0005)$, from 0 -load to 4-load $(p<.0005)$, and from 2-load to 4-load $(p<.0005)$.

In sum, behavioral data from the WM task confirm that the manipulation of WM load was successful as reaction times and percentage of false alarms increased and the percentage hits decreased when WM load increased.

Name-Face Stroop Task Performance and Effects of WM Load Average reaction times and the average percentage of false alarms, misses, and hits to Stroop stimuli as a function of Congruency and WM load are summarized in Table 2.

Accuracy. Since the average percentage of misses was smaller than $1 \%(.36)$, these data were not further analyzed. False alarms were higher for incongruent trials than for congruent trials (Congruency: $F(1,29)=37.4, p<.0005$ ), but there was no main effect of $\operatorname{Load}(F(2,58)=1.9, p=.16)$, and no interaction of Load $\times$ Congruency $(F(2,58)<1, p=.56)$. Hits were lower for incongruent trials than for congruent trials (Congruency: $F(1,29)=19.0, p<.0005)$. Although there was no interaction of Load $\times$ Congruency $(F(2,58)<1.0, p=.39)$, a main effect of 
Load $(F(2,58)=29.6, p<.0005)$ indicated an overall decrease in hits in the Stroop task when load increased. Planned comparisons showed a significant decrease in hits from 0-load to 2-load

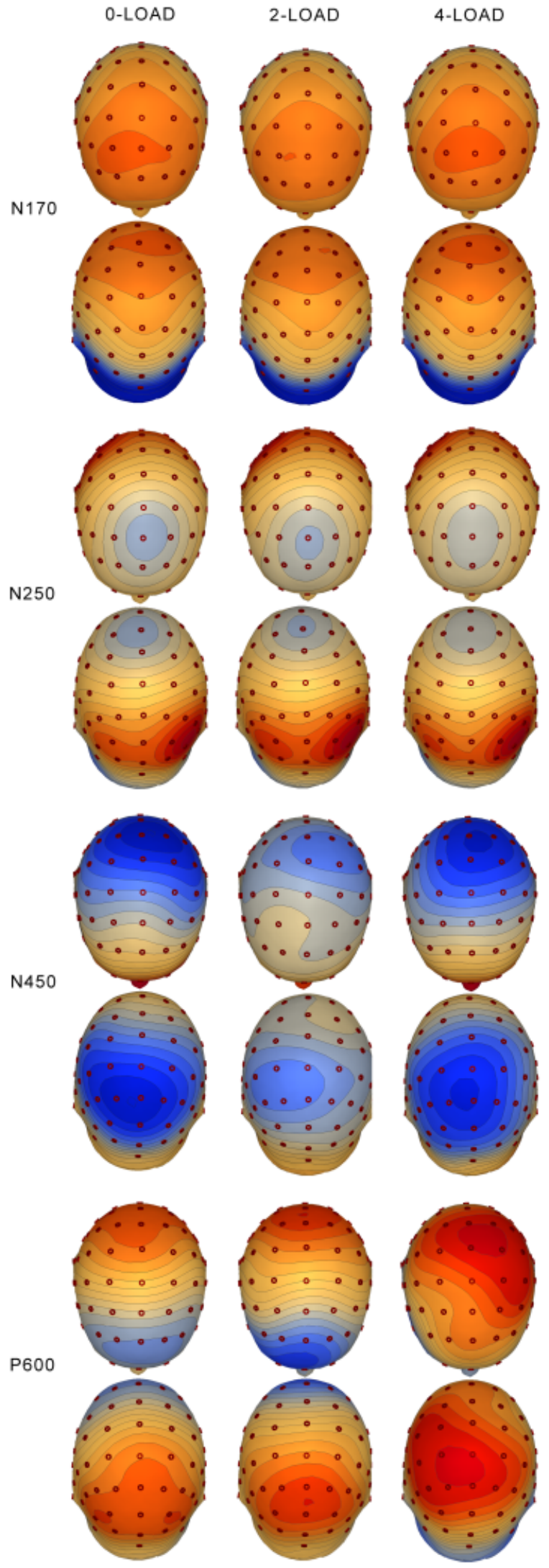

$(p<.0005)$ and from 0 -load to 4-load $(p<.0005)$, but not from 2load to 4-load $(p=.49)$.

Reaction time. As expected, reaction times were slower for incongruent trials than congruent trials (Congruency: $F(1,29)=147.0, p<.0005)$. Although there was no interaction of Load $\times$ Congruency $(F(2,58)<1, p=.46)$, a main effect of Load $(F(2,58)=13.1, p<.0005)$ indicated an overall increase in reaction time when load increased. Planned comparisons showed a significant increase in reaction time from 0-load to 2-load $(p=.008)$ and from 0-load to 4-load $(p=.001)$, and a trend from 2-load to 4-load $(p=.06)$.

In sum, the behavioral data provide evidence for interference in the name-face Stroop task as reaction times and the percentage of false alarms were higher and the percentage of hits was lower in incongruent trials than congruent trials. Although WM load led to an overall decrease in accuracy and an overall increase in reaction time, interference effects were not modulated by WM load.

\section{Event-Related Potentials}

N170 (180-220 ms). On N170 amplitude, there was no main effect of Congruency $(F(1,29)<1, p=.81)$, and no interaction of Load $\times$ Congruency $(F(1,29)=1.6, p=.21)$, but as shown in Figure 2, N170 amplitude decreased with WM load . N170 voltage maps for every load condition are shown in Figure 4. This was confirmed by a main effect of $\operatorname{Load}(F(2,58)=4.7, p=.01)$, indicating a linear decrease in amplitude with Load, as confirmed by a significant linear $(F(1,29)=9.3, p=.005)$ but not quadratic contrast $(F(1,29)<1, p=.85)$. Planned comparisons showed no difference in N170 amplitude between the 2-load condition and the 0 -load condition $(p=.19)$, but there was a significant amplitude reduction in the 4-load condition relative to the 0-load condition $(p=.005)$, and a trend reduction in the 4-load relative to the 2-load condition $(p=.096)$.

On N170 peak latency, there were no effects of Load $(F(2,58)=1.6, p=.22)$, Congruency $(F(1,29)<1, p=.82)$, or Load $\times$ Congruency $(F(1,29)=1.2, p=.29)$.

N250 (280-340 ms). On N250 amplitude, there was no main effect of Congruency $(F(1,29)=1.0, p=.32)$, or an interaction of Load $\times$ Congruency $(F(1,29)=1.7, p=.19)$, but as shown in Figure 2, N250 amplitude decreased with WM load. N250 voltage maps for every load condition are shown in Figure 4. This was confirmed by a main effect of $\operatorname{Load}(F(2,58)=6.1, p=.005)$, that was dependent on Hemisphere (Load $\times$ Hemisphere:

Figure 3. Grand average voltage maps of the N170 (180-220 ms), N250 (280-340 ms), N450 positivity reduction Stroop effect $(480-600 \mathrm{~ms})$, and P600 positivity enhancement Stroop effect ( $760-1000 \mathrm{~ms})$, in the different load conditions. For every component, the first row represents the front distribution, and the second row represents the back distribution of the scalp. N170 and N250 effects were computed by averaging the congruent and incongruent condition in every load condition, and N450 and P600 Stroop effects were computed by subtracting the congruent from the incongruent condition in every load condition. These distributions illustrate that, whereas the N170 and N250 effects are mainly distributed over lateral occipital-temporal sites, both Stroop effects were broadly distributed over the scalp. Red regions indicate positive voltages and blue regions indicate negative voltages. The electrode positions are indicated by dots and the difference between contour lines corresponds to a voltage change of $0.50 \mu \mathrm{V}$ for the $\mathrm{N} 170$ and $\mathrm{N} 250$, and a voltage change of 0.13 $\mu \mathrm{V}$ for the Stroop effects. 
Table 1. Working Memory Performance: The Means (M) and Standard Deviations (SD) of Reaction Time (in Milliseconds), and Percentages Hits, False Alarms, and Misses for the Different Memory Load Conditions (0, 2, 4)

\begin{tabular}{|c|c|c|c|c|c|c|c|c|}
\hline \multirow[b]{2}{*}{ Memory load } & \multicolumn{2}{|c|}{ Hits } & \multicolumn{2}{|c|}{$\begin{array}{l}\text { False } \\
\text { alarms }\end{array}$} & \multicolumn{2}{|c|}{ Misses } & \multicolumn{2}{|c|}{ Reaction time } \\
\hline & $M$ & $S D$ & $M$ & $S D$ & $M$ & $S D$ & $M$ & $S D$ \\
\hline 0 & 99.5 & 0.83 & 0.2 & 0.6 & 0.2 & 0.6 & 507.4 & 55.2 \\
\hline 2 & 93.1 & 4.3 & 6.4 & 4.1 & 0.6 & 1.1 & 689.1 & 103.1 \\
\hline 4 & 92.7 & 5.9 & 6.5 & 4.8 & 0.8 & 1.8 & 744.2 & 109.2 \\
\hline
\end{tabular}

$F(2,58)=4.1, p=.03)$, and significant only in the left hemisphere $($ PO7: $F(2,58)=9.3, p<.0005$; PO8: $F(2,58)=1.7, p=.19)$. For the left-hemispheric Load effect, the linear contrast $(F(1,29)=7.8, \quad p=.009)$ and the quadratic contrast $(F(1,29)=11.1, p=.002)$ were both significant. Planned comparisons showed an $\mathrm{N} 250$ reduction for the 2-load condition relative to the 0 -load condition $(p<.0005)$, and for the 4-load condition relative to the 0 -load condition $(p=.009)$, but there was no difference between the 4-load and the 2-load condition $(p=.22)$.

Positivity reduction ( $N 450$ effect: $480-600 \mathrm{~ms}$ ). As shown in Figure 3 and 4, there was an N450 effect, a positivity amplitude reduction in incongruent trials relative to congruent trials around $500 \mathrm{~ms}(480-600 \mathrm{~ms})$ that was distributed over frontocentral, centroparietal, parietal, and parieto-occipital sites. The effect is most clearly demonstrated by the difference waves of incongruent minus congruent trials, in Figure 3B, and the N450 voltage maps of these difference waves in Figure 4. Analyses confirmed the main effect of Congruency $(F(1,29)=34.6, p<.0005)$. The Congruency effect was not modulated by Load (Load $\times$ Congruency: $F(2,58)<1, p=.55)$, and there was no main effect of Load $(F(2,58)<1, p=.62)$. There was an interaction of Congruency $\times$ Anterior-Posterior $(F(3,87)=10.5, p=.001)$, and of Congruency $\times$ Anterior-Posterior $\times$ Laterality $(F(6,174)=2.7, p=.04)$. Inspection of means indicated that the amplitude reduction for the incongruent relative to the congruent condition was largest at midline centroparietal and parietal sites.

Table 2. Name-Face Stroop Performance: The Means (M) and Standard Deviations (SD) of Reaction Time (in Milliseconds), and Percentages Hits, False Alarms, and Misses for the Different Memory Load Conditions (0, 2, 4), and Congruency Conditions (Congruent, Incongruent)

\begin{tabular}{|c|c|c|c|c|c|c|c|c|c|}
\hline \multirow{2}{*}{$\begin{array}{l}\text { Memory } \\
\text { load }\end{array}$} & \multirow[b]{2}{*}{ Congruency } & \multicolumn{2}{|c|}{ Hits } & \multicolumn{2}{|c|}{$\begin{array}{l}\text { False } \\
\text { alarms }\end{array}$} & \multicolumn{2}{|c|}{ Misses } & \multicolumn{2}{|c|}{$\begin{array}{l}\text { Reaction } \\
\text { time }\end{array}$} \\
\hline & & $M$ & $S D$ & $M$ & $S D$ & $M$ & $S D$ & $M$ & $S D$ \\
\hline \multirow[t]{2}{*}{0 -Load } & Congruent & 97.1 & 2.5 & 2.4 & 2.2 & 0.2 & 0.5 & 672.4 & 87.2 \\
\hline & Incongruent & 93.1 & 4.3 & 5.9 & 3.9 & 0.3 & 0.6 & 708.7 & 82.1 \\
\hline \multirow[t]{2}{*}{ 2-Load } & Congruent & 91.3 & 5.5 & 2.0 & 1.8 & 0.2 & 0.5 & 690.9 & 83.7 \\
\hline & Incongruent & 88.8 & 5.6 & 4.4 & 3.2 & 0.5 & 1.1 & 726.1 & 85.6 \\
\hline \multirow[t]{2}{*}{ 4-Load } & Congruent & 90.5 & 6.6 & 2.5 & 2.3 & 0.5 & 0.8 & 699.1 & 91.5 \\
\hline & Incongruent & 87.6 & 6.6 & 5.5 & 3.8 & 0.5 & 0.9 & 742.2 & 100.7 \\
\hline
\end{tabular}

In sum, there was a load-independent positivity reduction (N450 Stroop effect) between 480-600 ms for incongruent trials relative to congruent trials that was broadly distributed and largest at (midline) centroparietal and parietal sites.

Positivity latency delay. As shown in Figure 3, the positivity showed a latency delay for incongruent trials (peak latency: 664 $\mathrm{ms}$ ) in comparison to congruent trials (peak latency: $644 \mathrm{~ms}$ ) (Congruency: $F(1,29)=51.7, p<.0005)$. There was an interaction of Congruency $\times$ Anterior-Posterior $(F(3,87)=21.8$, $p<.0005)$, and follow-up analyses showed that the latency delay was stronger at posterior sites (FC: $F(1,29)=9.6, p=.004$; CP: $F(1,29)=39.8, \quad p<.0005 ; \quad \mathrm{P}: \quad F(1,29)=65.1, \quad p<.0005$; PO: $F(1,29)=80.2, p<.0005)$. There were no effects of Load $(F(2,58)=3.1, p=.07)$, or Load $\times$ Congruency $(F(2,58)=1.6$, $p=.22)$ on latency.

Positivity enhancement ( $P 600$ effect: $760-1000 \mathrm{~ms}$ ). Later in time, there was a P600 effect, a positivity amplitude enhancement in incongruent trials relative to congruent trials that started around $760 \mathrm{~ms}$ and was distributed over frontal, fronto-central, parietal, and occipital sites, as shown in Figures 3 and 4. This positive amplitude difference is more clearly demonstrated by the difference waves of incongruent minus congruent trials, in Figure $3 \mathrm{~B}$, and the P600 voltage maps of these difference waves in Figure 4. Analyses confirmed the main effect of Congruency $(F(1,29)=21.1, p<.0005)$. In addition, there was an interaction of Load $\times$ Congruency $(F(2,58)=8.6, p=.001)$, Congruency $\times$ Anterior-Posterior $(F(3,87)=14.7, p<.0005)$, and Load $\times$ Congruency $\times$ Anterior-Posterior $(F(6,174)=2.9, p=.05)$. The three-way Load $\times$ Congruency $\times$ Anterior-Posterior interaction was further explored by testing for Load $\times$ Congruency interactions at frontal, frontocentral, parietal, and occipital sites. There were Load $\times$ Congruency interactions at frontal $(F(2,58)=10.0, \quad p<.0005) \quad$ fronto-central $\quad(F(2,58)=8.8$, $p=.001)$, and parietal sites $(F(2,58)=4.7, p=.02)$, but at occipital sites there was a main effect of Congruency $(F(1,29)=32.3, \quad p<.0005 ; \quad$ Load $\times \quad$ Congruency: $F(2,58)=1.2, p=.30)$. Follow-up analyses at frontal and fronto-central sites showed a Congruency effect in the 4-load condition (frontal: $F(1,29)=20.8, \quad p<.0005$; fronto-central: $F(1,29)=23.4, \quad p<.0005)$, but not in the 0-load (frontal: $F(1,29)=1.1, p=.29$; fronto-central: $(F(1,29)<1, p=.56)$ or 2-load (frontal: $F(1,29)=1.5, \quad p=.23 ; \quad$ fronto-central $(F(1,29)<1, p=.88)$ condition. At parietal sites, there was a Congruency effect in every load condition $(0$-load: $F(1,29)=7.1$, $p=.01$; 2-load: $F(1,29)=10.8, p=.003$; 4-load: $F(1,29)=26.6$, $p<.0005)$, and the Congruency effect linearly increased with Load as confirmed by a significant linear $(F(1,29)=7.6, p=.01)$ but not quadratic $(F(1,29)=1.8, p=.19)$ contrast. To verify that the frontal effect in the 4-load condition was not the result of volume conduction arising from enhanced activity of a common centroparietal source, Current Source Density (CSD) maps for the 4-load Congruency effect were computed in the 760-1000 ms time interval. These maps indicated different sources underlying the fronto-central and parietal effects. In sum, a positivity enhancement (P600 Stroop effect) between 760-1000 ms for incongruent trials relative to congruent trials at parietal sites increased with load, and at frontal and fronto-central sites was 
A

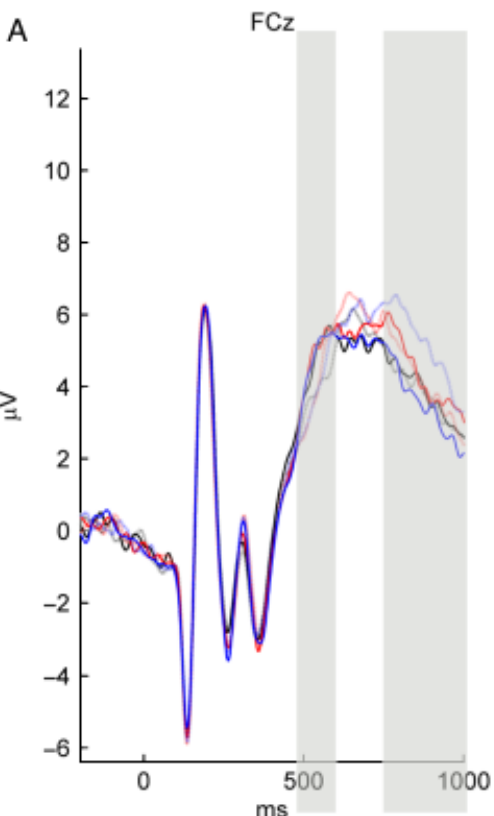

B

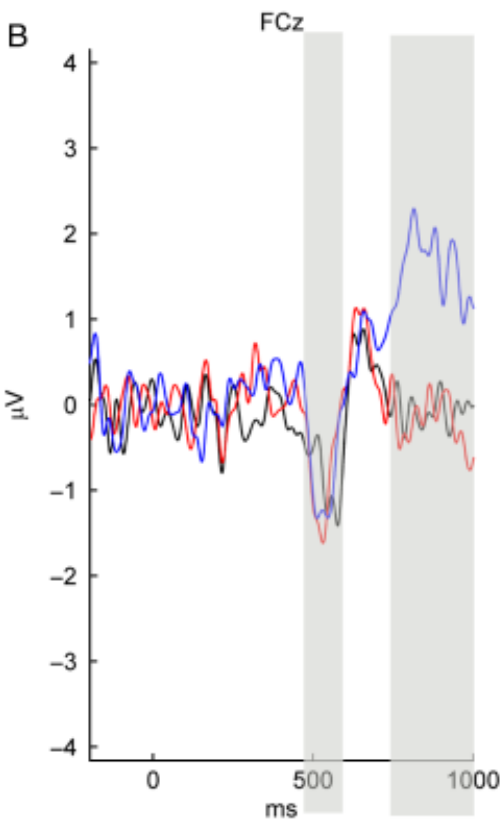

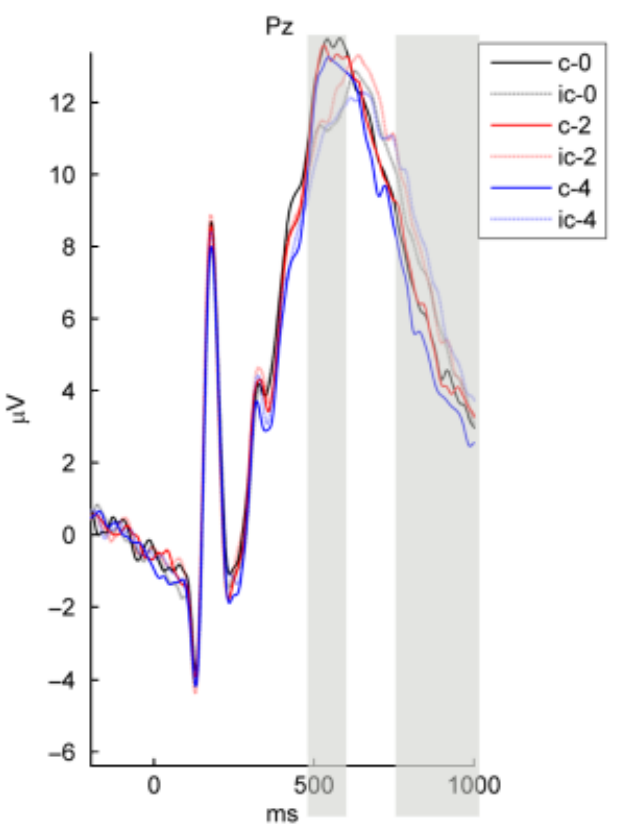

$\mathrm{Pz}$

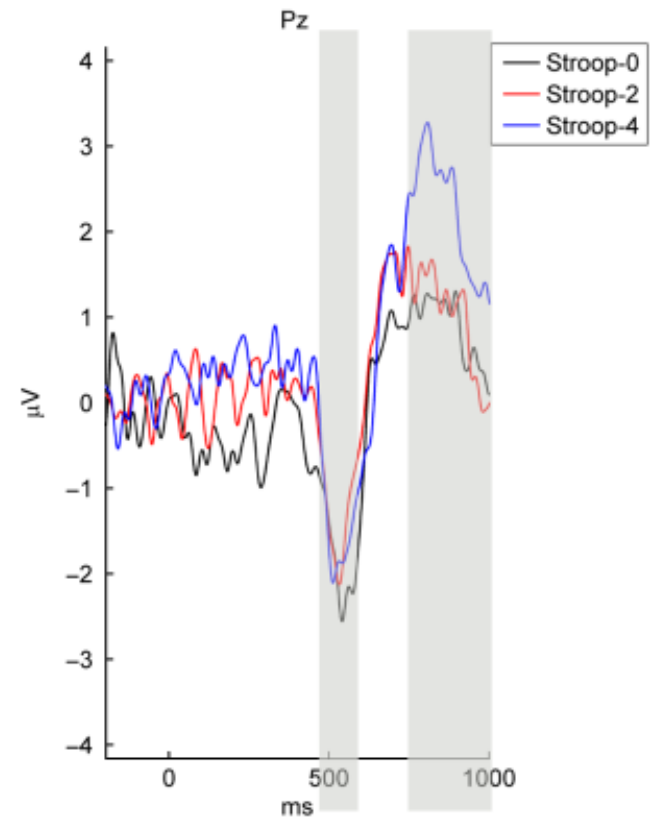

Figure 4. ERP responses elicited by name-face Stroop stimuli at FCz and Pz. Gray-colored bars indicate the N450 positivity reduction (480-600 ms) and P600 positivity enhancement (760-1000 ms). (A) Grand-averaged ERPs for congruent (c) and incongruent (ic) Stroop trials in the 0-load (black lines), 2load (red lines), and 4-load (blue lines) conditions. The latency delay of the positivity for incongruent trials in comparison to congruent trials is clearly visible. (B) Stroop difference waves of incongruent minus congruent trials in the 0-load (black lines), 2-load (red lines), and 4-load (blue lines) conditions. The effects were not limited to the electrodes shown here; see the text for the exact selection of electrodes used in statistical tests.

only present in the 4-load condition. Finally, at occipital sites the positivity enhancement was load-independent.

\section{Discussion}

Whereas prior studies have shown behavioral evidence for enhanced distractor interference when subjects have reduced capacity of WM, the present study for the first time examined the brain mechanisms involved in such WM capacity and interference control interactions over time. To this aim, ERPs were measured in a combined WM and name-face Stroop task that has been shown to elicit reliable distractor interference effects (De Fockert et al., 2001; Egner \& Hirsch, 2005; Pecchinenda \& Heil, 2007). Below, first behavioral results are discussed, followed by a discussion of the ERP results.

Behavioral results. Stroop interference in the behavioral results was reflected by a reaction time delay and an increase in false alarms for incongruent trials relative to congruent trials. In addition, the WM manipulation was successful as response times to the memory probes increased and accuracy decreased when WM was loaded. 
Contrary to our hypotheses and results in two prior studies using highly similar paradigms (De Fockert et al., 2001; Pecchinenda \& Heil, 2007), the behavioral Stroop interference effect was not modulated by WM load. It is unlikely that this is caused by differences in processing demands of our Stroop or WM task. Stroop interference effects in the 0-load condition were similar to those reported in other studies using a comparable face-name Stroop task (De Fockert et al., 2001; Egner \& Hirsch, 2005). Furthermore, the highest memory load of 4 letters compromised Stroop accuracy performance to the same extent in our study as in the study by De Fockert in which 5 digits were held in memory, pointing to a similar perceived load amount. Finally, lack of power cannot explain the absence of an interaction as our study included the largest number of subjects as compared to other studies using the same paradigm. Instead, a closer comparison between studies revealed that, whereas our results showed significant interference effects of category incongruent faces on reaction time and ERPs in the 0-load and 2load conditions, no reaction time Stroop effect was found in the low memory condition of the study by Pecchinenda and Heil (2007). Our finding of interference effects even when there was no WM load in the category face-name Stroop task replicates findings reported by Egner and Hirsch (2005; $36 \mathrm{~ms}$ and $41 \mathrm{~ms}$, respectively). Also, our mean Stroop reaction times were comparable to those reported by De Fockert et al. $(750 \mathrm{~ms})$ and Egner and Hirsch $(800 \mathrm{~ms})$, whereas those reported by Pecchinenda and Heil were remarkably fast (330-440 ms). In our study, as in the studies by De Fockert et al. and Egner and Hirsch, there were interference effects for reaction time and accuracy, pleading against a speed-accuracy trade-off. Pecchinenda and Heil did not report Stroop accuracy results, so possibly their subjects traded speed for accuracy (explaining the fast response times) as a result of the subject-paced nature of their task. This might then explain the absence of interference effects in the low WM load condition in their task, causing the interaction effect between WM load and Stroop interference in their results. Another explanation for the absence of WM load effects on behavioral Stroop interference might be that the participants in our study prevented a further increase in behavioral interference with increasing WM load by enhancing top-down frontal cortical control. The ERP data that will now be discussed provide evidence for such an explanation. Possibly, participants on average had a higher WM capacity than participants in other studies as it has been shown that subjects with higher capacity show more frontal cortex recruitment in demanding WM tasks (Osaka et al., 2003).

ERP results: Effects of WM load on distractor encoding. Based on WM load theory of selective attention (De Fockert et al., 2001; Lavie, 1995), our predictions were that, with an increase in WM load, top-down inhibitory control on distractor face processing would be reduced. During early processing stages of encoding, when face identification had not yet taken place, this reduced control was expected to lead to enhanced processing of all distractor faces, independent of (category-) congruency with the target name. Accordingly, main effects of WM load were found on the amplitude of the early occipitaltemporal N170 and N250 components that reflect early processes of face encoding and recognition, respectively, and have been localized to secondary visual areas (Bentin et al., 1996; Itier \& Taylor, 2004; Latinus \& Taylor, 2006; Pfütze et al., 2002; Schweinberger \& Burton, 2003; Schweinberger et al., 2002b).
However, instead of an increase, both components showed an amplitude reduction when load increased, suggesting reduced encoding of distractor face stimuli in secondary visual areas with higher WM load. This result is in contrast with results from fMRI studies that showed increased activation in visual cortical areas associated with distractor processing with increases of WM load (De Fockert et al., 2001; Rissman, Gazzaley, \& D'Esposito, 2009). Due to limited time resolution of fMRI, it is, however, difficult to determine whether this increased fMRI activation is related to encoding or later stages of conscious recognition or identification represented by ERP components occurring after about $400 \mathrm{~ms}$. Our time-sensitive ERP results show that during early perceptual encoding stages distractor processing is reduced with increases of WM load.

These results are supported by the ERP dual-task literature that consistently showed that an increase in difficulty of a primary task (i.e., the WM task) leads to reduced processing of secondary task stimuli (i.e., Stroop stimuli) due to less availability of resources (Jonkman et al., 2000; Kok, 2001; Singhal \& Fowler, 2004; Wickens, 1984). However, in contrast to these dual-task studies, the present study specifically investigated WM load effects on selective attention by investigating effects on distractor interference processing in a Stroop paradigm in which target and distractor stimuli were presented simultaneously. It has to be noted, however, that since in our Stroop stimuli faces and names were superimposed and the N170 and N250 are elicited by face and name stimuli (e.g., Mercure, Dick, Halit, Kaufman, \& Johnson, 2008; Pfütze et al., 2002; Schweinberger et al., 2002b), the early modulations of N170 and N250 amplitude in our results cannot unequivocally be related to the processing of distractor (face) stimuli. Still, the hypothesized topdown effect of memory load on early Stroop stimulus encoding occurred, but in another direction than WM load theory would predict.

A recent delayed recognition ERP study reported a similar amplitude reduction of the face-sensitive N170 and N250 responses to memory face probes when participants retained an increasing number of faces in WM (Morgan et al., 2008). It was suggested that N170 and N250 processing resources necessary for face processing of the memory probe item were reduced because the same resources were used by WM maintenance of face stimuli. In our study, ERPs were not measured to memory probes, but to secondary (Stroop)-task stimuli that were presented in the maintenance interval and that were not part of the memory set. The present results thus suggest shared resources for WM maintenance of the letter stimuli and early processing of the Stroop stimuli, as reflected by N170 and N250 amplitude reductions. Such shared resources may originate in secondary visual cortex areas as it has been shown that maintenance of a memory set, especially during distraction, requires prefrontal cortex (PFC)-controlled updating of stimulus representations in the visual cortex (Johnson, Mitchell, Raye, D'Esposito, \& Johnson, 2007; Yi, Turk-Browne, Chun, \& Johnson, 2008). Since in our study the to-be-maintained stimuli were letters and early processing of letters has been shown to take place also in fusiform areas (Wong, Gauthier, Woroch, DeBuse, \& Curran, 2005), the refreshing of memory letter presentations during distraction, especially in the high 4-load condition, may require so much fusiform activation that early distractor processing in overlapping areas is compromised. The fact that the N250 WM load effect was left lateralized further adds to this conclusion. This reduced early perceptual encoding and recognition of Stroop stimuli 
might be related to the increase in false alarms and reaction time when WM load increased.

ERP results: Effects of WM load on distractor interference processing. ERP findings confirmed our predictions that nameface Stroop interference occurs later in time, starting around 450 $\mathrm{ms}$ after face and name identification and recollection of semantic information regarding occupation (e.g., Bentin \& Deouell, 2000; Eimer, 2000a, b; Paller et al. 2000; Pfütze et al., 2002; Schweinberger et al., 2002b). First, delayed peak latencies of a broadly distributed positivity when face-identity was categoryincongruent with the to-be-categorized name indicate longer stimulus evaluation and identification time (Kutas et al., 1977) for incongruent than congruent stimuli. A similar positivity delay for incongruent trials in comparison with congruent trials has been shown in a color-word Stroop task (Lansbergen \& Kenemans, 2008). Second, incongruent stimuli evoked an amplitude reduction of a broadly distributed positivity between $480-600 \mathrm{~ms}$ after stimulus onset. A similar amplitude reduction, the N450, has repeatedly been shown in color-word Stroop studies and has been related to conflict detection (e.g., Lansbergen et al., 2007; Liotti et al., 2000; Markela-Lerenc et al., 2004; Qiu et al., 2006; West, 2003; West et al., 2004). This is to our knowledge the first time it has been shown in a name-face Stroop task. The latency delay and N450 effects were of comparable strength in the three load conditions, suggesting that these processes of conflict detection proceed without WM involvement and that neural circuits involved in conflict detection and WM maintenance do not overlap or share resources.

The N450 effect was followed by an interference effect between 760-1000 ms at frontal, fronto-central, parietal, and occipital sites, consisting of a positivity enhancement for incongruent trials relative to congruent trials (P600 effect). A similar broadly distributed P600 effects has consistently been demonstrated in color-word Stroop ERP studies and has been related to processes of conflict resolution and the processing of response-relevant (color) information that is used to guide response selection in incongruent trials (e.g., Jongen \& Jonkman, 2008; Lansbergen et al., 2007; Liotti et al., 2000; West, 2003; West \& Alain, 2000). Our results show that this interference effect is modulated by WM load at frontal, fronto-central, and parietal sites, but not at occipital sites. More specifically, it increased linearly with load at parietal sites, and at frontal and frontocentral sites, it was restricted to the highest WM load condition. These results are in line with models of cognitive control that assign an important role to the PFC in maintenance of goals and the means to achieve them (Duncan, 2001; Fuster, 2001; Miller, 2000; Miller \& Cohen, 2001). According to these models, topdown biasing signals are sent from the PFC to different structures throughout the brain, thereby guiding behavior by affecting, for example, sensory modalities, systems responsible for response selection or execution, and systems for memory retrieval. This guiding activity is assumed to be especially important when, in a task such as a Stroop task, multiple responses are possible for a given stimulus, and the task-appropriate response must compete with stronger, more automatic alternatives (e.g., MacDonald, Cohen, Stenger, \& Carter, 2000).

Important for the interpretation of the present results, evidence for such PFC driven top-down control on posterior faceprocessing areas has been shown in an fMRI study using a similar face-name Stroop task (Egner \& Hirsch, 2005). More specifically, in conditions in which participants exerted high cognitive control, there was a behavioral decrease in interference that was accompanied by enhanced PFC activation and, more importantly, enhanced functional connectivity between PFC areas and posterior target processing areas. It was argued that conflict resolution thus was embodied by PFC-driven modulation of posterior areas, biasing processing of relevant information. Taking the above findings into account, it seems reasonable to assume that the present enhanced fronto-central activation in response to incongruent Stroop trials only in the 4-load condition indicates enhanced cognitive control that was necessary to reduce the extra interference resulting from resource depletion by the concurrent high WM load. This extra PFC control has presumably led to successful prevention of an increase in behavioral interference, explaining the absence of an interaction between WM load and interference in our reaction time results. The parietal interference effects that increased linearly with WM load are suggested to reflect enhanced processing of response-relevant information used to guide response selection incongruent trials (Jongen \& Jonkman, 2008; Lansbergen et al., 2007; Liotti et al., 2000; West, 2003; West \& Alain, 2000), possibly prompted by PFC. To conclude, our ERP results extend the current literature on the interaction between WM and selective attention by showing that a concurrent high WM load of 4 letters causes the strongest bottlenecks in a late stage of interference processing, associated with conflict resolution or response selection. Such late effects of WM load were also reported in another ERP study, in which targets and distractors were presented sequentially (SanMiguel, Corral, \& Escera, 2008).

Finally, it might be argued that the fact that the enhanced frontal activation to incongruent stimuli in the 4-load condition occurs at or after the average response times for incongruent trials (between 700 and $750 \mathrm{~ms}$ ) complicates a functional relation with the process of conflict resolution. However, it has been noted in the mental chronometry ERP literature that "the respective components do not necessarily have to emerge in the ERP waveform at exactly the same times as the corresponding stages take place. A residual delay could intervene between execution of a stage and the occurrence of its associated ERP component. Other ancillary stages outside the mainstream of processing could also be immediate precursors of the components and lengthen their latencies" (Meyer, Osman, Irwin, \& Yantis, 1988, p. 46). Therefore, with respect to the delay between average response times and the latency window of the positivity enhancement in our data, this does not exclude the functional relation of the positivity enhancement to conflict resolution.

In sum, using ERP measures this study for the first time examined when, in time, name-face Stroop interference is modulated by WM demands. The first name-face interference effect occurred around $500 \mathrm{~ms}$ (N450 effect), during stages of stimulus evaluation and conflict detection, and was followed by a second interference effect between 760-1000 ms (P600 effect), related to conflict resolution. WM load only modulated the P600 effect: there was a linear increase of the P600 interference effect with WM load at parietal sites, and at fronto-central sites it was restricted to the highest WM-load condition. These effects are suggested to reflect enhanced PFC-driven top-down control of posterior sites in highly demanding situations when enhancement of target stimulus processing and suppression of distractor stimulus processing are necessary for conflict resolution. Successful conflict resolution by enhanced PFC recruitment probably explains the absence of modulations by WM load on behavioral interference. 


\section{REFERENCES}

Allison, T., Ginter, H., McCarthy, G., Nobre, A. C., Puce, A., Luby, M., et al. (1994). Face recognition in human extrastriate cortex. Journal of Neurophysiology, 71, 821-825.

Baddeley, A. (1993). Working memory or working attention? In A. Baddeley \& L. Weiskrantz (Eds.), Attention: Selection, awareness, and control (pp. 152-170). Oxford, England: Oxford University Press.

Begleiter, H., Porjesz, B., \& Wang, W. (1995). Event-related brain potentials differentiate priming and recognition to familiar and unfamiliar faces. Electroencephalography and Clinical Neurophysiology, 94, 41-49.

Beringer, J. (1987). Experimental Run Time System (Version 3.32c). Frankfurt: Berisoft Cooperation.

Bentin, S., Allison, T., Puce, A., Perez, E., \& McCarthy, G. (1996). Electrophysiological studies of face perception in humans. Journal of Cognitive Neuroscience, 8, 551-565.

Bentin, S., \& Deouell, L. Y. (2000). Structural encoding and identification in face processing: ERP evidence for separate mechanisms. $\mathrm{Cog}$ nitive Neuropsychology, 17, 35-54.

Boehm, S. G., \& Sommer, W. (2005). Neural correlates of intentional and incidental recognition of famous faces. Cognitive Brain Research, 23, 153-163.

Bötzel, K., Schulze, S., \& Stodieck, S. R. (1995). Scalp topography and analysis of intracranial sources of face-evoked potentials. Experimental Brain Research, 104, 135-143.

Bruce, V., \& Young, A. (1986). Understanding face recognition. British Journal of Psychology, 77(Pt 3), 305-327.

Conway, A. R. A., Cowan, N., \& Bunting, M. F. (2001). The cocktail party phenomenon revisited: The importance of working memory capacity. Psychonomic Bulletin \& Review, 8, 331-335.

Corbetta, M., \& Shulman, G. L. (2002). Control of goal-directed and stimulus-driven attention in the brain. Nature Reviews Neuroscience, 3, 201-215.

De Fockert, J. W., Rees, G., Frith, C., \& Lavie, N. (2001). The role of working memory in visual selective attention. Science, 291, 1803-1806.

Duncan, J. (2001). An adaptive coding model of neural function in prefrontal cortex. Nature Reviews Neuroscience, 2, 820-829.

Egner, T., \& Hirsch, J. (2005). Cognitive control mechanisms resolve conflict through cortical amplification of task-relevant information. Nature Neuroscience, 8, 1784-1790.

Eimer, M. (2000a). Effects of face inversion on the structural encoding and recognition of faces: Evidence from event-related brain potentials. Cognitive Brain Research, 10, 145-158.

Eimer, M. (2000b). Event-related brain potentials distinguish processing stages involved in face perception and recognition. Clinical Neurophysiology, 111, 694-705.

Fuster, J. M. (2001). The prefrontal cortex - an update: Time is of the essence. Neuron, 30, 319-333.

Gazzaley, A., Cooney, J. W., McEvoy, K., Knight, R. T., \& D’Esposito, M. (2005). Top-down enhancement and suppression of the magnitude and speed of neural activity. Journal of Cognitive Neuroscience, 17, 507-517.

Heitz, R. P., \& Engle, R. W. (2007). Focusing the spotlight: Individual differences in visual attention control. Journal of Experimental Psychology: General, 136, 217-240.

Herzmann, G., Schweinberger, S. R., Sommer, W., \& Jentzsch, I. (2004). What's special about personally familiar faces? A multimodal approach. Psychophysiology, 41, 688-701.

Itier, R. J., \& Taylor, M. J. (2004). Effects of repetition learning on upright, inverted and contrast-reversed face processing using ERPs. NeuroImage, 21, 1518-1532.

Johnson, M. R., Mitchell, K. J., Raye, C. L., D’Esposito, M., \& Johnson, M. K. (2007). A brief thought can modulate activity in extrastriate visual areas: Top-down effects of refreshing just-seen visual stimuli. NeuroImage, 37, 290-299.

Jongen, E. M. M., \& Jonkman, L. M. (2008). The developmental pattern of stimulus and response interference in a color-object Stroop task: An ERP study. BMC Neuroscience, 9, 82.

Jongen, E. M. M., Smulders, F. T. Y., \& van Breukelen, G. J. P. (2006). Varieties of attention in neutral trials: Linking RT to ERPs and EEG frequencies. Psychophysiology, 43, 113-125.

Jongen, E. M. M., Smulders, F. T. Y., \& van der Heiden, J. S. H. (2007). Lateralized ERP components related to spatial orienting: Discrimi- nating the direction of attention from processing sensory aspects of the cue. Psychophysiology, 44, 968-986.

Jonkman, L. M., Kemner, C., Verbaten, M. N., Van Engeland, H., Camfferman, G., Buitelaar, J. K., \& Koelega, H. S. (2000). Differences between children with attention-deficit hyperactivity disorder and normal control children and effects of methylphenidate. Psychophysiology, 37, 334-346.

Kane, M. J., Conway, A. R. A., Bleckley, M. K., \& Engle, R. W. (2001). A controlled-attention view of working-memory capacity. Journal of Experimental Psychology: General, 130, 169-183.

Kane, M. J., \& Engle, R. W. (2003). Working-memory capacity and the control of attention: The contributions of goal neglect, response competition, and task set to Stroop interference. Journal of Experimental Psychology: General, 132, 47-70.

Kim, S.-Y., Kim, M. S., \& Chun, M. M. (2005). Concurrent working memory load can reduce distraction. Proceedings of the National Academy of Sciences, 102, 16524-16529.

Kok, A. (2001). On the utility of P3 amplitude as a measure of processing capacity. Psychophysiology, 38, 557-577.

Kutas, M., McCarthy, G., \& Donchin, E. (1977). Augmenting mental chronometry: The P300 as a measure of stimulus evaluation time. Science, 197, 792-795.

LaBar, K. S., Gitelman, D. R., Parrish, T. B., \& Mesulam, M. M. (1999). Neuroanatomic overlap of working memory and spatial attention networks: A functional MRI comparison within subjects. NeuroImage, 10, 695-704

Lansbergen, M. M., \& Kenemans, J. L. (2008). Stroop interference and the timing of selective response activation. Clinical Neurophysiology, 119, 2247-2254.

Lansbergen, M., Van Hell, E., \& Kenemans, J. L. (2007). Impulsivity and conflict in the Stroop task. Journal of Psychophysiology, 21, 33-50.

Latinus, M., \& Taylor, M. J. (2006). Face processing stages: Impact of difficulty and the separation of effects. Brain Research, 1123, 179187

Lavie, N. (1995). Perceptual load as a necessary condition for selective attention. Journal of Experimental Psychology: Human Perception and Performance, 21, 451-468.

Lavie, N. (2005). Distracted and confused?: Selective attention under load. Trends in Cognitive Sciences, 9, 75-82.

Lavie, N., \& De Fockert, J. (2005). The role of working memory in attentional capture. Psychonomic Bulletin and Review, 12, 669-674.

Lavie, N., Hirst, A., De Fockert, J. W., \& Viding, E. (2004). Load theory of selective attention and cognitive control. Journal of Experimental Psychology: General, 133, 339-354.

Lavie, N., Ro, T., \& Russell, P. (2003). The role of perceptual load in processing distractor faces. Psychological Science, 14, 510-515.

Liotti, M., Woldorff, M. G., Perez, R. III, \& Mayberg, H. S. (2000). An ERP study of the temporal course of the Stroop color-word interference effect. Neuropsychologia, 38, 701-711.

MacDonald, A. W. III, Cohen, J. D., Stenger, V. A., \& Carter, C. S. (2000). Dissociating the role of the dorsolateral prefrontal and anterior cingulate cortex in cognitive control. Science, 288, 1835-1838.

Markela-Lerenc, J., Ille, N., Kaiser, S., Fiedler, P., Mundt, C., \& Weisbrod, M. (2004). Prefrontal-cingulate activation during executive control: Which comes first? Cognitive Brain Research, 18, 278-287.

Mayer, J. S., Bittner, R. A., Nikolic, D., Bledowski, C., Goebel, R., \& Linden, D. E. J. (2007). Common neural substrates for visual working memory and attention. NeuroImage, 36, 441-453.

McNab, F., Leroux, G., Strand, F., Thorell, L., Bergman, S., \& Klingberg, T. (2008). Common and unique components of inhibition and working memory: An fMRI, within-subjects investigation. Neuropsychologia, 46, 2668-2682.

Mercure, E., Dick, F., Halit, H., Kaufman, J., \& Johnson, M. H. (2008). Differential lateralization for words and faces: Category or psychophysics? Journal of Cognitive Neuroscience, 20, 2070-2087.

Meyer, D. E., Osman, A. M., Irwin, D. E., \& Yantis, S. (1988). Modern mental chronometry. Biological Psychology, 26, 3-67.

Miller, E. K. (2000). The prefrontal cortex and cognitive control. Nature Reviews Neuroscience, 1, 59-65.

Miller, E. K., \& Cohen, J. D. (2001). An integrative theory of prefrontal cortex function. Annual Reviews Neuroscience, 24, 167-202.

Morgan, H. M., Klein, C., Boehm, S. G., Shapiro, K. L., \& Linden, D. E. J. (2008). Working memory load for faces modulated P300, 
N170, and N250r. Journal of Cognitive Neuroscience, 20, 9891002 .

Osaka, M., Osaka, N., Kondo, H., Morishita, M., Fukuyama, H., Aso, T., \& Shibasaki, H. (2003). The neural basis of individual differences in working memory capacity: An fMRI study. NeuroImage, 18, 789797.

Paller, K. A., Bozic, V. S., Ranganath, C., Grabowecky, M., \& Yamada, S. (1999). Brain waves following remembered faces index conscious recollection. Cognitive Brain Research, 7, 519-531.

Paller, K. A., Gonsalves, B., Grabowecky, M., Bozic, V. S., \& Yamada, S. (2000). Electrophysiological correlates of recollecting faces of known and unknown individuals. NeuroImage, 11, 98-110.

Paller, K. A., Ranganath, C., Gonsalves, B., LaBar, K. S., Parrish, T. B., Gitelman, D. R., et al. (2003). Neural correlates of person recognition. Learning and Memory, 10, 253-260.

Park, S., Chun, M. M., \& Kim, M. S. (2007). Concurrent working memory load can facilitate selective attention: Evidence for specialized load. Journal of Experimental Psychology: Human Perception and Performance, 33, 1062-1075.

Pecchinenda, A., \& Heil, M. (2007). Role of working memory load on selective attention to affectively valent information. European Journal of Cognitive Psychology, 19, 898-909.

Pessoa, L., \& Ungerleider, L. G. (2004). Top-down mechanisms for working memory and attentional processes. In M. S. Gazzaniga (Ed.), The new cognitive neurosciences (pp. 919-930. MIT Press.

Pfütze, E., Sommer, W., \& Schweinberger, S. R. (2002). Age-related slowing in face and name recognition: Evidence from event-related brain potentials. Psychology and Aging, 17, 140-160.

Pollmann, S., \& von Cramon, D. Y. (2000). Object working memory and visuospatial processing: Functional neuroanatomy analyzed by eventrelated fMRI. Experimental Brain Research, 133, 12-22.

Qiu, J., Luo, Y., Wang, Q., Zhang, F., \& Zhang, Q. (2006). Brain mechanism of Stroop interference in Chinese characters. Brain Research, 1072, 186-193.

Redick, T. S., \& Engle, R. W. (2006). Working memory capacity and Attention Network Test performance. Applied Cognitive Psychology, 20, 713-721.

Rissman, J., Gazzaley, A., \& D'Esposito, M. (2009). The effects of nonvisual working memory load on top-down modulation of visual processing. Neuropsychologia, 47, 1637-1646.

Rossion, B., Campanella, S., Gomez, C. M., Delinte, A., Debatisse, D., Liard, L., et al. (1999). Task modulation of brain activity related to familiar and unfamiliar face processing: An ERP study. Clinical Neurophysiology, 110, 449-462.

SanMiguel, I., Corral, M., \& Escera, C. (2008). When loading working memory reduces distraction: Behavioral and electrophysiological evidence from an auditory-visual distraction paradigm. Journal of Cognitive Neuroscience, 20, 1131-1145.

Schweinberger, S. R., \& Burton, M. (2003). Covert recognition and the neural system for face processing. Cortex, 39, 9-30.

Schweinberger, S. R., Huddy, V., \& Burton, M. (2004). N250r: A faceselective brain response to stimulus repetitions. NeuroReport, 15, 1501-1505.
Schweinberger, S. R., Pfütze, E. M., \& Sommer, W. (1995). Repetition priming and associative priming of face recognition. Evidence from event-related potentials. Journal of Experimental Psychology: Learning, Memory, and Cognition, 21, 722-736.

Schweinberger, S. R., Pickering, E. C., Jentzsch, I., Burton, M., \& Kaufman, J. M. (2002a). Event-related brain potential evidence for a response of inferior temporal cortex to familiar face repetitions. Cognitive Brain Research, 14, 398-409.

Schweinberger, S. R., Pickering, E. C., Burton, M., \& Kaufman, J. M. (2002b). Human brain potential correlates of repetition priming in face and name recognition. Neuropsychologia, 40, 2057-2073.

Semlitsch, H. V., Anderer, P., Schuster, P., \& Presslich, O. (1986). A solution for reliable and valid reduction of ocular artifacts, applied to the P300 ERP. Psychophysiology, 23, 695-703.

Singhal, A., \& Fowler, B. (2004). The differential effects of Sternberg short- and long-term memory scanning on the late Nd and P300 in a dual-task paradigm. Cognitive Brain Research, 21, 121-134.

Smulders, F. T. Y., Kenemans, J. L., \& Kok, A. (1994). A comparison of different methods for estimating single-trial P300 latencies. Electroencephalography and Clinical Neurophysiology: Evoked Potentials, 92, 107-114.

Sreenivasan, K. K., \& Jha, A. P. (2007). Selective attention supports working memory maintenance by modulating perceptual processing of distractors. Journal of Cognitive Neuroscience, 19, 32-41.

Tanaka, J. W., Curran, T., Porterfield, A. L., \& Collins, D. (2006). Activation of preexisting and acquired face representations: The N250 event-related potential as an index of face familiarity. Journal of Cognitive Neuroscience, 18, 1488-1497.

West, R. (2003). Neural correlates of cognitive control and conflict detection in the Stroop and digit-localisation tasks. Neuropsychologia, 41, 1122-1135.

West, R., \& Alain, C. (2000). Age-related decline in inhibitory control contributes to the increased Stroop effect observed in older adults. Psychophysiology, 37, 179-189.

West, R., Bowry, R., \& McConville, C. (2004). Sensitivity of medial frontal cortex to response and nonresponse conflict. Psychophysiology, 41, 739-748.

Wickens, C. D. (1984). Processing resources in attention. In R. Parasuraman \& R. Davies (Eds.), Varieties of attention (pp. 63-101). New York: Academic Press.

Wong, A. C., Gauthier, I., Woroch, B., DeBuse, C., \& Curran, T. (2005). An early electrophysiological response associated with expertise in letter perception. Cognitive, Affective, \& Behavioral Neuroscience, 5, 306-318.

Woodman, G. F., Vogel, E. K., \& Luck, S. J. (2001). Visual search remains efficient when visual working memory is full. Psychological Science, 12, 219-224.

Yi, D., Turk-Browne, N. B., Chun, M. M., \& Johnson, M. K. (2008). When a thought equals a look: Refreshing enhances perceptual memory. Journal of Cognitive Neuroscience, 20, 1371-1380.

(ReCEIVED January 27, 2009; ACCEPTED January 6, 2010) 